\title{
Fostering Digital Skills and \\ Competencies Through Discursive \\ Mapping of Information Landscapes
}

Andrew Whitworth

\section{Introduction: A Statement of the Problem}

The digitalisation of society requires the fostering of new skills and competencies in learners. Higher education (HE) institutions across the EHEA are expected to develop these, preparing graduates for positions in industry, civic and private life in which they will be expected to make informed judgments using a range of information sources and tools for finding, organising and communicating information, whether individually or in collaboration. These tools and sources are arrayed around the learner in what Lloyd (2010) calls an "information landscape", and the skills and competencies involved-digital and information literacy (DIL) - are those which help learners map and navigate this landscape (Whitworth 2020).

This paper describes how this view of DIL, as mapping, can be observed emerging in learners as they work on collaborative tasks in a HE environment. This is DIL as more than just technical competencies, considered present if a learner can use particular software applications (as defined, for example, in the European Computer Driving License or ECDL), and beyond whether students know how to access information sources considered appropriate in the academic setting (such as journals). Rather (Polizzi 2019. 1, emphasis added):

In order to contribute to the active participation of well-informed and critically autonomous citizens in democracy in the digital age, critical digital literacy needs to include knowledge about the digital environment where information circulates.

This broader view aligns with the EU's vision of a curriculum that ensures that not just the young but all citizens are "able to creatively, critically and productively take part in a digital society" (Redecker and Punie 2017, 12). The EU's Digital Competence Framework (Carretero et al. 2017: hereafter, DigComp) includes both 'information and data literacy' and 'communication and collaboration' as core elements. When

\footnotetext{
A. Whitworth $(\bowtie)$

University of Manchester, Manchester, UK

e-mail: drew.whitworth@manchester.ac.uk 
the digital competence of educators is also considered (Redecker and Punie 2017), digital teaching and learning skills include collaborative learning and self-regulation, as the competent digital educator, in turn, facilitates learners' digital competence through engaging them with DIL, communication, content creation, responsible use and problem- solving with digital technologies (ibid, 8).

However, the pedagogical structures and didactic approaches needed to develop these competencies in learners are not yet fully understood or addressed in HE. The work of Lloyd (2010, 2012) emphasises that instilling DIL skills in ways that support students' academic studies will not necessarily be transferable beyond the university. Workplace and civic information landscapes and the informational problems to which they give rise are structured in different ways (Lloyd 2010; Bruce 2008). In HE, learning outcomes are more stable and regulated, more individual, and more structured. In the workplace, although information needs are often more tightly defined, learning is also a 'fuzzier', less definable and more collaborative process. In other words, the information landscapes of HE and work are different in form, and the skills required to navigate them successfully are also different.

Early on in Information Literacy Landscapes Lloyd says (2010, 2, emphasis added):

Information landscapes are the communicative spaces that are created by people who coparticipate in a field of practice. As people journey into and through these landscapes they engage with site-specific information. This engagement allows them to map the landscape, constructing an understanding of how it is shaped. It is through this engagement that people situate themselves within the landscape.

Just as one can learn about a physical landscape, its general configuration and the specifics of the resources within it through mapping the landscape, so Lloyd is suggesting that the same principles can apply to an information landscape. But she does not offer detail on what might be happening when learners learn to map information landscapes in this way, and what the implications are for course and assessment design within HE.

Transferability of knowledge from place to place must be more than just replication of a learned process because in different places, different practice architectures inevitably exist. But being an effective user of diverse information systems, knowing how to navigate a landscape, making effective use of communications media to disseminate insights: these are reflexive capacities that help learners (Alkemeyer and Buschmann 2016, 11, emphasis added) 'become able to adjust and improve their participation in the context of not just one practice but many similar practices in a process of learning self-structuration'. This is an educational process that requires attending to different modalities of information outlined by Lloyd (2010, 161ff);

- the epistemic modality, meaning disciplinary knowledge appropriate to a given setting. This is the modality typically emphasised in HE assessment.

- the social modality, that is, "sources from the situated experience of collective participation, practice and reflection on action.... closely associated with reflection and reflexivity about professional practice and professional identity" (ibid, 164). 
- the corporeal modality, "disseminated through demonstration and observation of practice or accessed through the tactile and kinaesthetic activity associated with actual practice" (ibid, 165).

This paper provides an outline of mapping as a discursive, dialogic process involved in exploring and constructing information landscapes, via engagement with all of these different modalities. Discursive mapping is a pedagogical concept that can help explore the development of digital competencies as outlined in the DigComp framework, particularly those of information/data literacy and communication/collaboration. Via an example in an online HE setting, the paper then explores how DIL can be integrated into assessment design.

\section{Theoretical Basis}

Despite stating more than once that mapping is beneficial for developing information literacy skills (see also Lloyd et al. 2013, 11), Lloyd provides little detail on what mapping might entail pedagogically. This detail is added by Whitworth's investigation (2020), where examples of mapping are analysed. He concludes that: "mapping has value in learning to use, nurture and steward information landscapes because it is a means by which representations of relationships between relevant landscape elements can be developed, communicated and scrutinised within communities."

Whitworth notes that the products of mapping are not limited to graphics, that is, maps in the everyday sense, including concept or mind maps. Mapping is also a fundamentally discursive practice; a way of forming knowledge and creating cognitive schema (Bartlett 1932), ways of thinking that can be used as the basis for later judgements. Making a map requires the mapmaker(s) to be positioned at focal points of information flows, to gather information, determine relevant elements, and represent these elements on the map field. All maps make propositions that can then be explored in the world (Kitchin et al. 2009, 13-14), propositions that are dialogic in form before they are graphical. Harvey states that (1996, p. 111):

The discursive activity of 'mapping space' is a fundamental prerequisite to the structuring of any kind of knowledge. All talk about 'situatedness', 'location' and 'positionality' is meaningless without a mapping of the space in which those situations, locations and positions occur. And this is equally true whether the space being mapped is metaphorical or real....

Harvey also notes that (1996, 283-4):

...multiple windows on a same reality, like the multiple theorisations available to us, can constitute a way of triangulating in on this same reality from multiple perspectives. Learning to see the world from multiple positions - if such an exercise is possible - then becomes a means to better understand how the world as a totality works.... This technique of conjoining information from different positionalities is a basic principle of all cartographic construction: to make an accurate map (representation) of the world we require at the very minimum a procedure of triangulation that moves across multiple points. 
This view of how knowledge - and maps of information landscapes - might be constructed is reflected in the work of Christine Bruce, who invokes the value of 'experiencing variation' (Bruce et al. 2006; Bruce 2008) in teaching DIL. Bruce exhorts those working in the 'relational frame' of DIL education to employ methods that give learners this experience of variation when making informational judgements, or as Harvey puts it, learning to see a situation from multiple perspectives and combining these perspectives into a map, a representation that can be communicated to others. Bruce suggests that this helps learners develop cognitive schema akin to those of professionals in a given discipline: she calls this informed learning (2008).

In HE, informed learning approaches must expand beyond teaching only the epistemic modality of information: the DigComp and DigCompEdu frameworks also make this move explicit. Other modalities must come into play when knowledge is successfully employed in a real-life situation (Badke 2012, 135-6, emphasis added): "Accumulated data require sense-making skills on two fronts-determining what is reliable/significant/relevant and organising the data into a structure that is manageable so that it can be used to address the issue at hand." These determinations are the practical manifestations of DIL. To make such determinations, and thereby select and organise relevant data and information, is a function of how individuals and groups bring cognitive schema to bear and articulate these schemas to discursively map the information landscape within which they are working.

Schemas are learned, stored ways of thinking and (Blaug 2007: 30):

function to pick out relevant, "schema-consistent" data from the rush of information we regularly confront. As such, they are pre-existing selection criteria that manage cognitive overload and enhance the capacity to solve problems.

Understanding and revealing the cognitive schemas which structure not just the epistemic knowledge relevant to a given discipline, but how it is shared, practiced and related to professional identity in that discipline (that is, the social and corporeal modalities), is an important aspect of higher education in that discipline. However, if learners are expected merely to accept the cognitive schemas with which they are presented, this would be surface learning, a (power-laden) transference of knowledge from the 'authoritative' disciplinarian (that is, the tutor) to the passive learner. DIL, however-a practical, material capacity that would empower learners to become and remain digitally competent, adaptable and responsive to problems they will face in the future-requires pedagogical practices that allow learners to make their own independent, justifiable, judgements about information and technology and thereby generate their own cognitive schemas.

The emphasis in the last sentence indicates that it is not the case that 'anything goes', cognitively, as long as it comes from a learner working independently (cf. Thompson 2008). There remains a role for the 'more able partner' who can review and, if necessary, critique the judgments, justifications and discursive maps that have been articulated: this partner may be a tutor or peer. Hepworth and Walton (2009, 156) describe the educational benefits of articulating judgements and the basis for them: 
Cognitive constructivist learning, from an individual perspective, relates to building a mental map of the information landscape. Presenting, explaining and justifying this 'map' helps the learner concretise and internalise this view. From a social constructivist perspective the learner is learning about the information artefacts and tools that a specific 'community' uses and values.... They learn to use the general language of sources, such as 'portal', 'full text', 'open access' or 'creative commons', or those specific to the domain.

\section{Research Basis}

In academic years 2015-16 and 2016-17, the SPIDER project (Stewarding and Power In Digital Educational Resources) studied 20 groups of 5-7 learners on a postgraduate course at a large UK university. These learners used discussion boards within a Blackboard virtual learning environment to complete a series of assessment tasks. The tasks (described in more detail in Webster and Gunter 2018; Whitworth 2020) gradually reduced the amount of information that was provided to groups, meaning members had to collaborate to gather information and make judgements of relevance, in order to propose collective solutions to problems posed. The course recruited a mixture of on-campus and distance learning students (Webster and Whitworth 2017), and every group contained representatives from both modes. Consequently, groups could not meet face-to-face in their entirety, and members were obliged to use these boards (and, as will be seen, other online platforms) to communicate.

A substantial proportion of these discussions in Blackboard were therefore recorded, and these accumulated into the SPIDER dataset. Over two years, this corpus amounts to over one million words, and in ongoing work, the SPIDER team are analysing these data to determine whether and how students use discursive mapping techniques as they integrate found information into their landscapes. Webster and Gunter (2018) also interviewed some of the students and the course tutor.

In formal educational settings, we should not expect shared goals and a sense of cohesion to emerge simply because a discussion board is presented to a group of students. Rather, thinking about how the learning activities can be structured and facilitated in ways that might give rise to this sense of community, is a pedagogical design task essential for developing collaboration and communication skills as called for by Digcomp. Pai et al. $(2015,80)$ note that "[s]tructures, such as scripts, roles, and group rewards, have been identified as critical for fostering greater learning in groups than in individual contexts..."; such "scripts" can be (ibid, 81): "designed to increase specific cognitive behaviours associated with learning, such as summarizing, providing explanations, or asking questions...". They cite Aronson's "Jigsaw" approach, in which (Pai et al. 2015, 81):

Each group member studies a subtopic of the material, meeting in "expert groups" to share information with peers from the other jigsaw groups specializing in the same subtopic, and then returning to their groups to teach their peers about their subtopic. Each student is like a piece in a jigsaw puzzle. Each part is essential for full understanding of the final product (Aronson 2002). 
To succeed at a task like this requires group members to develop effective information selection and management skills. Therefore, and, most importantly (ibid, 82-3, emphases added):

when working in groups, multiple perspectives on the problem need to be negotiated to a common representation. Therefore, the representation tends to be abstract to be able to bridge various views. Collaboration provides an environment to generate more abstract representations which is not normally available when working alone.... While working collaboratively, individuals have to generate and explain their thoughts to each other. Vocalizing one's thoughts can help to produce an organized cognitive structure of the material...

These emphasised points strongly allude to discursive mapping, and the value it can have. Pai et al. suggest that by articulating their positions, a common representation, or 'organised cognitive structure', can emerge among the student group. And the fact that these positions are being explicitly articulated and recorded on the online discussion boards is also significant (Walton and Cleland 2017). The online environment-Blackboard, in this case-is not just an inert space, nor even just a recording device; it is a constitutive part of the information landscape, and has a variety of features and affordances which students can bring to bear when it comes to selecting, mapping (or organising) and communicating information. The board becomes the "basis for shared meaning" and permits these educational practices.

Students were assessed with reference to a marking rubric (made public to them) that valued practices such as citation of the literature, taking on particular roles in the discussion, sustained rather than sporadic participation and so on (the full rubric is given in Whitworth 2020). In all, the assessment specification, the marking rubric, and structures of facilitation and support within this course are designed to promote certain informational practices, conducive to informed learning (Bruce 2008), over others. The design of these activities offers a framework, or practice architecture, in which students get practical experience in building an information landscape that helps them meet collective learning goals. They must set up a sociotechnical information system, one that helps them make selections, organise information and disseminate findings. And as postings on the discussion boards are graded, the dialogues taking place as the group work together are not happening in camera, but are visible, open to scrutiny by the course tutor, the students themselves, and finally, the SPIDER research team.

\section{Findings}

The groups' initial information configuration can be termed their 'starter' landscape (or habitat-Wenger et al. 2009). It is provided by the tutor but is a habitat without inhabitants. For the first task - the discussion of an academic paper (viz, Mishra and Koehler 2006) - groups are provided with all the information they need to complete it (the paper itself). But in the second task, a role-playing simulation, and the third, a design task, groups must develop and extend their 'starter' landscape by gathering more information than is provided to them. 
Based on their prior experience and judgments of relevance, oriented by their subjective understanding of tool affordances and their interpretation of how best to configure the landscape so the group can meet its shared learning needs (Wenger et al. 2009), groups introduce new resources into this 'starter' habitat. These resources may be informational and come from online sources or the literature, as these quotes illustrate (see also Whitworth and Webster 2019):

Here is the link for the text "Knowledge for Literacy" as a reference: http://www. shankerinstitute.org/blog/knowledgeliteracy.

In my university... to be innovative in technology or deliver teaching in a different way is questioned, not by the faculty, but by higher management who see it as not conforming to the standard norms students are used to.

Since technologies are changing very fast, we must also relearn and readapt our own teaching practice. Mishra and Koehler say that technological knowledge is 'the ability to learn and adapt to new technologies' (page 1028).

We see here, respectively, the provision of information via URL; via narrative and personal experience; and via academic citation.

As well as these informational resources, students introduce technological tools into the landscape. This is rare in the first activity, but after that experience, groups frequently note that the discussion boards have limited functionality, and so, through a series of informed judgments, introduce other tools to colleagues. For example:

$M e,[D]$ and $[S]$ just had a Skype planning meeting to think things over; here's a summary of the discussion and what we will be doing.

Other groups use different tools. For example, Padlet becomes part of the habitat configured by four groups but not the others. Student [B] here introduces Padlet to his group. He draws on his professional experience and suggests associated information practices:

In class, I like to use padlet.com to create discussion boards and students have even used it to do group work. I've created a padlet with the information. It's a huge poster board where we can all add information. I've added all the information [tutor] has provided and a quick comment. Let me know what you think? Should we give it a try?

On occasion, individuals suggest reasons to avoid particular technologies (remember, these utterances are not made post hoc to an interviewer but to group members, via the boards):

The main problem I find with LinkedIn is that it's overrun with recruitment agents, so I rarely use it. Twitter is OK for some stuff, but because it's so transient I find I miss things a lot and it feels like a lot of effort to keep up with it.

This from Webster and Gunter $(2018,79)$ who quote an interviewee (unlike the ones above, then, this comment is made post hoc rather than on the boards):

Our own VLE proved to be tricky sometimes. ...I valued that, as a team, we made use of different ways to communicate, group our ideas and give shape to our preliminary decision and strategy. Gmail, Facebook, Google Drive, and the chat room in Blackboard helped us explore the use of social media and Web 2.0 tools to better communicate and write collaboratively. 
By the end of the series of activities, each group's learning environment thereby looks different from those of other groups and different from the 'starter habitat'. The group's information landscape has evolved, becoming a record of the judgments of relevance that have been made by members. The landscapes have layers that sediment out (Lloyd 2010, 9-10) of discussions and interactions that students have with each other and with the tutor and teaching assistant. Judgments are based on the prior experience of individuals, and their application of DIL in work and everyday life, and are validated by colleagues according to their relevance for the specific, shared task that the group has to complete. Group members learn practices that help them work together and are in a dynamic, mutually reinforcing relationship with the technologies and sources that they introduce into the landscape. As Wenger et al. (2009, 137) write: "Shared assumptions about how to use [the technologies] constitute practice."

Groups also reflect on their performance and consider how the practices, technologies and resources in the habitat might be better used subsequently:

$M e,[Y]$ and $[S] \ldots$ have already discussed on how we should form our thread in this forum so that it'll better organized than our previous discussion (Hehehee.. we think it was pretty cluttered).

In each group, what emerges is a set of shared assumptions about the landscape, and ways of navigating it most effectively. Thus far then, these illustrations have shown how group members establish a structure for their information landscapes.

Groups also apply a mapping process to the material contexts- that is, the places-which are foci for these activities, giving group members a single, shared focus for the judgments of relevance they must make. Through discursive mapping, members co-create a representation of a landscape that becomes the basis for further judgments. This aligns with Steinerova (2010) findings regarding information behaviour in academic settings and the value of graphical and discursive mapping in helping with both phases of such work - the initial orientation stage, in which learners survey the field and gather information into a landscape, and the analytic stage, where on the basis of what was found and structured in the orientation stage, decisions are reached. (See also Kuhlthau 1993.)

These stages are most evident in activity 2 , in which the groups must make judgments about a context that is fictitious, as it first exists only as the scenario presented by the tutor, outlining a problem faced by "Mackenzie College". But students can be observed working to map and, thus, reach agreement on their views of this context and the problems it faces. As noted in Whitworth andWebster (2019, emphasis added);

Members of the groups can be observed introducing and validating informational and technological resources to other group members, and working to configure their information landscape in ways that then allow them to make judgments about found or encountered information in ways that could not have been possible for them prior to the dialogue.

The scenario outlines the problem and offers advice about issues that the groups might consider. But the landscape provided in these notes is limited, and students are 
told this. In the orientation stage, groups must bring further information into their landscape, incorporating resources that they judge to be relevant, including citations from the literature, and information gleaned from other groups, playing different roles (the groups in each simulation are: senior management; IT services; the student body; an innovative group of 'tech-savvy' teaching staff; and other teaching staff).

As a result of this information search and subsequent discussion, groups develop their own perspectives on the scenario, answering for themselves the question of how "Mackenzie" should formulate its e-learning strategy. Contrast these posts, from two different groups playing the same role, the IT services department. Both groups started with the same initial information (the scenario), but come to agree on different priorities. For the first group, these are speed of access and students' accessing the VLE after graduation; for the second, wifi, training and teaching.

Questions we (the IT team) have to deal with by the end of this week: What should/can we do to make the VLE a faster platform? Can we get in touch with the provider and see if they have any updates coming up next year? For sure, we don't want to move into a different VLE. Is there a possibility for us to help the students maintain their access after they graduate? This might be a real satisfier for the students.

So far our ideas seem to be around: Changes in infrastructure: potential investment in wif; Changes in teaching: potential changes in the adoption of apps as an IT team we need to look at how we could support this both through infrastructure and possible training. This might be a potential digital change agent project (students and staff working together).

What is significant is how these interpretations of the context-that is, groups' discursive maps of "Mackenzie College" - are carried forward and used as the basis for judgements made in the analytic stage. The transition takes place after the "management' group communicate the outcome of their own group deliberations, a draft e-learning strategy for Mackenzie. Other groups then publish their collective reaction to this decision. Take this quote, for example, made by the group playing the 'tech-savvy' academics:

... this is good information for us to use and saves us time.... this strengthens our argument for 'going it alone' and they recognise us as being well trained.

This judgement - that the conclusions reached by the management group strengthen this group's argument for "going it alone" with educational technology —is authentically made, even though it refers to a simulated context. There is no external "reality" to Mackenzie, and therefore, any criteria against which the group (or any other group) bases its judgments must be that which they negotiate and agree upon through intraand inter-group dialogue. These dialogues allow groups to agree upon basic informational constructs, such as priorities and problems for Mackenzie. These constructs become the basis for the judgments of relevance that each group makes when it comes to analysing the 'management' decision.

For example, largely because of its containing student [R], a distance learner employed as an academic librarian, the group quoted here was the only one of the 20 groups to draw attention to the fact that the library was not discussed in the original scenario. The rest of the group concur with [R]'s judgement, and thereafter the library 
becomes an evident part of this group's discursive map of Mackenzie in a way it does not for other groups. Responding to the management group's decision, [R] writes:

Have the management integrated the librarians, the students want this, and we do too. How is the new situation an improvement for us? Will it make any difference to our teaching and delivery of our courses and our research? I think we need more support from the management and more recognition.

In the same group discussion, student $[\mathrm{A}]$ here quotes information from the scenario (the indented paragraph) and builds on it with a judgment about what is the best next step for the group to take within this simulated situation:

we already have long experience with this issue because we manage to teach distance learners. In other words, our expertises have formed as a response to learning process which is distance learning.

'Mackenzie's distance learning programmes are highly rated and are led by a team of academics/researchers who are internationally regarded as innovators in the teaching of History at a distance. '

So, I suggest to contact with managers team to discuss the idea of introducing our experience to other colleagues either IT team or other academic team?

[R] agrees with [A] that this will have benefits for their group:

this could be a good opportunity for us to improve our profile at the university and therefore to get some recognition for the quality of teaching we deliver in the department.

Although the context is simulated, these things can be confidently stated because the discursive map that they have negotiated and reached consensus on has been integrated into their information landscape, and for each group, is now no less "real" than the assessment task itself. A "register of correspondence" (Cosgrove 1999, 1) has developed between the place about which decisions are being made (in this case, Mackenzie) and the discursive map that the group have performatively created via their discussion on the boards, which can guide their own self-assessment, help them scrutinise judgments made. The map helps the group make connections between informational resources, becoming an agreed-upon basis for action that does not need to be renegotiated and can serve as the basis for group judgments of relevance regarding found and offered information. A map makes propositions; and these propositions can be explored in the world, that is, the place represented upon the map. It does not matter that Mackenzie has no physical cognate: it nevertheless acts as an information ground, a "sociophysical location" (Hultgren 2009, 140) which both facilitates access to information and makes it relevant.

\section{Discussion and Conclusion}

For a student to make any proposition to their peers-asserting the value of an online resource, say, or offering an idea for how Mackenzie should develop its digital strategy - they must articulate that proposition on the discussion board, making 
an utterance of some kind that contributes to the discursive map. Responses to these utterances, whether they come from the tutor or, in more in-depth ways in this setting, from peers, validate and position each claim to knowledge. As exhorted by Bruce (2008), they are learning to see the world from multiple positions, 'experiencing variation' and thus triangulating on the landscape (Harvey 1996, 283-4); bringing multiple perspectives together in a single interpretive framework, or discursive map. At least for the duration of the activity, the map becomes a locus of collective memory (Harvey 1996, 417). The technological tools in use (Blackboard); the regime of assessment; and the subsequent SPIDER research methodology: all are processes that (in different ways) have given the dialogue permanence and revealed the dialogic moves that are made by the learners as they construct, map and navigate their information landscapes.

Effective pedagogical design for informed learning involves this placing of the learner, giving them a position from which they can develop a perspective on the landscape. That does not mean it is desirable for students to stay in this place. Instead, the position should be seen as a starting point from which they can learn to navigate the landscape: a map that they can expand upon, review and redraw if their investigations require it. In the example discussed here, these possibilities are opened up firstly by the design of the activities, and then the signposting by tutors and peers of additional resources that may be useful in the landscape. Learners in these groups teach one another mapping and other information practices, rather than being reliant on the tutor. These stewarding processes (Wenger et al. 2009) turn the assessment specification from a plan (which 'extinguishes contextual potential') into a map, a tool for exploration, 'a generative means, a suggestive vehicle that "points" but does not overly determine' (Corner 1999, 228). This is illustrated by the variety of 'Mackenzies' which come into being and the different practical settings in which students actively apply their knowledge.

While the disciplinary context explored must be different in each case, this is an approach to the development of and assessment of informed learning that could be applied across the EHEA. The DigComp elements of information/data literacy and communication and collaboration are directly reflected in the pedagogical framework explored in this paper. The SPIDER research indicates how informed learning approaches like this one integrate DIL into teaching in a way that would improve the chances of institutions meeting their obligations to graduates, preparing them more fully to enter the workplace and civic life and developing a broad set of competencies in DIL. As Badke notes (2012, 93):

... educators are going to need to move from teaching about their disciplines to enabling their students to become disciplinarians. The expression, 'welcome to my world', encapsulates the goal ... We must invite students into our world and there reproduce ourselves in them, turning our students into active practitioners in our disciplines.

As Lloyd has noted, to "turn students into active practitioners" requires engagement with more than just the disciplinary knowledge or epistemic modality, but the social 
and corporeal modalities. Through work with all the modalities, digital and informational competencies can be addressed in ways sympathetic to the DigComp and DigCompEdu frameworks.

\section{References}

Alkemeyer, T., \& Buschmann, N. (2016). Learning in and across practices: Enablement as subjectivation. In A. Hui, T. Schatzki, \& E. Shove, (Eds.), The Nexus of Practices: Connections, constellations, practitioners (pp. 20-35). Routledge.

Badke, W. B. (2012). Teaching Research Processes: The faculty role in the development of skilled student researchers. Oxford: Chandos.

Bartlett, F. C. (1932). Remembering: A study in experimental and social psychology. Cambridge University Press.

Blaug, R. (2007). Cognition in a Hierarchy. Contemporary Political Theory6(1), 24-44.

Bruce, C. S. (2008). Informed Learning. ACRL.

Bruce, C. S., Edwards, S. L. \& Lupton, M. (2006) Six Frames for Information literacy Education: a conceptual framework for interpreting the relationships between theory and practice. Innovation in Teaching and Learning in Information and Computer Sciences, 5(1), 1-18.

Carretero, S., Vuorikari, R., \& Punie, Y. (2017). The Digital Competence Framework for Citizens. Publications Office of the European Union.

Corner, J. (1999) The agency of mapping: Speculation, critique and invention. In Cosgrove, D. (Ed.), Mappings (pp. 213-252), Reaktion.

Cosgrove, D. (1999). Mappings. Reaktion.

Harvey, D. (1996). Justice, Nature and the Geography of Difference. Blackwell.

Hepworth, M. and Walton, G. (2009): Teaching Information Literacy for inquiry-based learning, Elsevier

Hultgren, F. (2009). Approaching the Future: A study of Swedish school leavers' information-related activities. Valfrid.

Kitchin, R., Perkins, C. \& Dodge, M. (2009). Thinking about maps. In Dodge, M., Kitchin, R. \& Perkins, C. (Eds.), Rethinking maps: New frontiers in cartographic theory (pp. 1-25), Routledge.

Kuhlthau, C.C. (1993). Seeking meaning: A process approach to library and information services. Westport, CT: Greenwood.

Lloyd, A. (2010). Information literacy landscapes: Information literacy in education, workplace and everyday contexts. Chandos.

Lloyd, A. (2012). Information literacy as a socially enacted practice: Sensitising themes for an emerging perspective of people-in-practice. Journal of Documentation68(6), 772-783.

Lloyd, A., Kennan, M. A., Thompson, K. M. \& Qayyum, A. (2013) Connecting with new information landscapes: information literacy practices of refugees, Journal of Documentation, 69(1), 121-44.

Mishra, P., \& Koehler, M. J. (2006). Technological pedagogical content knowledge: A framework for teacher knowledge. Teachers college record, 108(6), 1017-1054.

Pai, H. H., Sears, D. A., \& Maeda, Y. (2015). Effects of small-group learning on transfer: A metaanalysis. Educational psychology review, 27(1), 79-102.

Polizzi, G. (2019). Information literacy in the digital age: why critical digital literacy matters for democracy. In Goldstein, S. (Ed.), Informed Societies: Why information literacy matters for citizenship, participation and democracy (pp. 1-24). Facet Publishing.

Redecker, C. \& Punie, Y. (2017). European framework for the digital competence of educators: DigCompEdu. No. JRC107466. Joint Research Centre (Seville site).

Steinerová, J. (2010). Ecological dimensions of information literacy. Information Research, 15(1).

Thompson, D. (2008), Counterknowledge, Atlantic. 
Walton, G., \& Cleland, J. (2017). Information literacy: empowerment or reproduction in practice? A discourse analysis approach. Journal of Documentation, 73(4), 582-594.

Webster, L. \& Gunter, H. (2018). How power relations affect the distribution of authority: implications for information literacy pedagogy. Journal of Information Literacy, 12(1).

Webster, L., \& Whitworth, A. (2017): Distance learning as alterity: facilitating the experience of variation and professional information practice. Journal of Information Literacy, 11(2).

Wenger, E., White, N., \& Smith, J. D. (2009). Digital Habitats: Stewarding Technology for Communities. CPSquare, Portland OR.

Whitworth, A. \& Webster, L. (2019). Digital and Information Literacy as Discursive Mapping of an Information Landscape. Proceedings LILG-2019 conference, Frankfurt.

Whitworth, A. (2020). Mapping Information Landscapes. Forthcoming, Facet Publishing.

Open Access This chapter is licensed under the terms of the Creative Commons Attribution 4.0 International License (http://creativecommons.org/licenses/by/4.0/), which permits use, sharing, adaptation, distribution and reproduction in any medium or format, as long as you give appropriate credit to the original author(s) and the source, provide a link to the Creative Commons license and indicate if changes were made.

The images or other third party material in this chapter are included in the chapter's Creative Commons license, unless indicated otherwise in a credit line to the material. If material is not included in the chapter's Creative Commons license and your intended use is not permitted by statutory regulation or exceeds the permitted use, you will need to obtain permission directly from the copyright holder. 